\section{A Computer Program for Record- keeping and Seedling Evaluation in Fruit Trees}

\author{
D. Bassi ${ }^{1}$, E. Muzzi ${ }^{2}$, P. Negri ${ }^{3}$, and R. Selli ${ }^{4}$ \\ Istituto di Coltivazioni Arboree, University of Bologna, V. Filippo Re 6, \\ 40126 Bologna, Italy
}

Additional index words. breeding, data collection, computer software

Data collection and processing in fruit-tree breeding programs have been performed mostly manually, which is time-consuming and also can be the source of transcription errors.

Breeders recently have had opportunities to implement a wide range of computer applications. These have included estimating the structure and genetic variation of populations (Dowling and Moore, 1984) and linkage and mutation frequency analysis (St. John et al., 1983). The availability of directly applicable programs, such as genotype-environment interaction characterization (Kang, 1985) and germplasm bank management (Styles et al., 1985), allows for increased effectiveness.

Fruit breeding programs have used data processing procedures to optimize operational management (V. Beres and R. Scorza, personal communication). Except for the use of punch cards (Fogle, 1974), computerization of procedures is scarcely mentioned in the literature, except, recently, in forestry research for direct field data collection

Received for publication 19 Dec. 1988. Mention of the name of a proprietary product is not to be construed as a recommendation of the product as superior to others that may be available. The cost of publishing this paper was defrayed in part by the payment of page charges. Under postal regulations, this paper therefore must be hereby marked advertisement solely to indicate this fact.

'Associate Professor.

${ }^{2}$ Programmer

${ }^{3}$ Research Fellow funded by E.R.S.O. (Cesena, Italy) for the peach breeding program.

${ }^{4}$ Doctoral Candidate in pomology.
(Manzari, 1987). Our paper reports the application of data processing techniques in the simplification and optimization of peach breeding.

In the past 10 years, more than 25,000 seedlings have been developed at the Univ. of Bologna's Istituto di Coltivazioni Arboree. Manual data collection and processing were found to be slow and unwieldy. Therefore, a portable Hewlett-Packard (HP) computer $75 \mathrm{C}$ and an HP 9816 were employed to collect and process data. A special software package, "Select", was also developed in BASIC 4.0. The data are codified according to several traits regarding tree, flowers, leaves, and fruits. Each seedling is assigned an eight-digit identification number; the first two indicating the year of cross, the next three a parent code, and the last three the field location. The "Select" program stores: a) parental identification of each seedling; b) field location of each seedling (sequential numbering); and c) data that include a maximum of 10 options or definitions for each item entered. Recorded traits can be changed as a function of collection time (bloom or ripening). A user guide card is provided to the operator for codified data input.

Data transference from the portable to the desk top computer (DT) is accomplished by means of an HPIL/HPIB converter. This conversion is implemented by two linkage routines via a parallel link to the DT. These routines allow for data transfer from portable to DT, subsequent disk storage, reading, and

The reading and codification routines sort each seedling by year and cross, while alcodification of data. lowing the operator to indicate whether an item is a new entry or an update. Each cross is then compared with those already stored in a service file. Unidentified crosses may be either errors or new inputs. These are rechecked and corrected, thereby enabling identification of updating of the service file. When coding is complete, data are placed in permanent files. There is also the option of loading the data manually into the DT.

Data can be analyzed and results expressed in absolute and percentage values using the DT. This analysis is performed on "depth first" or "breadth first" criteria. Both can isolate the seedling on file in terms of the characters to be analyzed. "Select" also includes routines for file management (ordering, separation, union) and addition, correction, or elimination of single characters.

The hardware employed generally was very reliable, both mechanically and operationally. While time required for data collection did not differ substantially from the conventional field registry approach, subsequent computer transfer, processing, and eventual correction proved to be extremely efficient. Moreover, potential errors due to data transcription were virtually eliminated. Inadvertent errors during field data collection (e.g., key punching) are, however, inescapable. Therefore, constant checking of portable computer data entry is advised to obviate mistakes. All the software described above is available on request on 3.5-inch micro flexible disks at a nominal cost.

\section{Literature Cited}

Dowling, T.E. and X.S. Moore. 1984. A program for estimating genetic variability within and between populations. J. Hered. 75:416.

Fogle, H.W. 1974. Portable punched cards for recording tree fruit evaluations. Fruit. Var. J. 28:2-6.

Kang, M.S. 1985. SAS program for calculating stability-variance parameters. J. Hered. 76:142143

Manzari, R. 1987. Piedilista di cavallettamento con il computer. Monti e boschi, 5:31-34.

Styles, E.D., J. Emphill, and S. Hayes. 1985. SNOBOL4 programs for processing genetic records, tracing pedigrees, and sorting genotypes. J. Hered, 76:143.

St. John, R. C., N. Shafer, and R.C. Woodruff. 1983. A computer analysis of the statistical significance of mutation rates. J. Hered. 74:8587. 